\title{
DIFERENCIAS ENTRE LA ACCIÓN DE DEMARCACIÓN Y LA ACCIÓN DE REIVINDICACIÓN. COMENTARIO SENTENCIA CORTE SUPREMA DE 17 DE AGOSTO DE 2010, ROL N ${ }^{\circ}$ 5565-2010
}

DIFFERENCES BETWEEN THE ACTION OF DEMARCATION AND THE VINDICATION ACTION. SUPREME COURT JUDGEMENT AUGUST 17, 2010, ROLE NO. 5565-2010

DIFFÉRENCES ENTRE L'ACTION DE DEMARCATION ET L'ACTION DE REVENDICATION. ARRÊT DE LA COUR SUPRÊME DE AOÛT 17, 2010, DOSSIER N ${ }^{\circ}$ 5565-2010

\section{Fabiola Lathrop Gómez*}

La demarcación -objeto que persigue la acción que lleva este nombre- es un conjunto de operaciones que tiene por objeto fijar la línea de separación de dos predios colindantes de distintos dueños, y señalarla por medio de signos materiales. En opinión de Peñailillo ${ }^{1}$, esta acción procede sea que el conflicto se deba a la realidad o a los títulos, es decir, tanto por discrepancias relativas a las marcas en el terreno como por oscuridad de los títulos en cuanto a la descripción de los deslindes. Además, según el autor, esta acción tiene por objeto pedir al juez que demarque, pero no recuperar terreno poseído por otro, aunque -agrega- cada parte allegará antecedentes para demostrar que la línea debe ser trazada por donde a ella le interesa.

Este último elemento es el que motiva el comentario de este fallo, en cuanto la disputa que en él se presenta se conecta con un problema mayor: el del régimen jurídico de protección del derecho de dominio y de la posesión en nuestro país.

Al referirse a la protección del derecho de dominio y la posesión, la mayoría de la doctrina chilena se ha centrado en el análisis de las acciones nominadas de protección, observándose, por el contrario, un escaso desarrollo de otras acciones no mencionadas expresamente por la ley ${ }^{2}$. Esto a diferencia de lo

\footnotetext{
* Abogada. Licenciada en Ciencias Jurídicas y Sociales de la Universidad de Chile. Doctora en Derecho por la Universidad de Salamanca. Docente e Investigadora de la Escuela de Postgrado de la Facultad de Derecho de la Universidad de Chile y Profesora de Derecho Civil del Departamento de Derecho Privado de la misma Facultad.

1 Cfr. Peñallillo Arévalo, Daniel. Los Bienes. Santiago: Editorial Jurídica, 2007, p.495.

2 En todo caso, cabe destacar los trabajos de Míguez Núñez, Rodrigo. "La acción negatoria”. Revista de Derecho de la Universidad Católica de la Santísima Concepción, No 12. Diciembre 2004, pp. 129-135 y, en lo que respecta a las inmisiones, Amunátegui Perelló, Carlos. "No siendo contra derecho ajeno: hacia la formulación de una teoría de las inmisiones
} 
sucedido en el Derecho comparado, donde la doctrina y, fundamentalmente la jurisprudencia, han construido, en materia de derechos reales, acciones como la confesoria y la negatoria, a falta de texto positivo.

En efecto, la doctrina chilena se ha abocado al estudio de la acción reivindicatoria que, por antonomasia, protege el dominio y la posesión de su titular, pero que, sin embargo, se ha tornado muchas veces ineficaz para conseguir tal propósito, debido, entre otros factores, a la conocida dificultad de prueba de los hechos constitutivos de la pretensión del actor, es decir, su dominio, y a la discusión acerca de si procede respecto de derechos personales y universalidades jurídicas ${ }^{3}$. No obstante, la falencia de la acción reivindicatoria radica, fundamentalmente, en la restricción de su ámbito de protección ${ }^{4}$ y en su tramitación en juicio de lato conocimiento, factores que debilitan su funcionamiento y conducen, inexorablemente, al ejercicio de otras acciones -muchas veces como subterfugio- que le están emparentadas, como la acción de precario y la de demarcación.

La llamada acción de precario del artículo 2195 inciso $2^{\circ} \mathrm{CC}$, al estar sustanciada en juicio sumario, ha tomado gran ventaja a la acción reivindicatoria 5 ; la acción de demarcación, por su parte, regulada en los artículos 844 y ss. CC -también sometida a un juicio sumario-, pese a perseguir, de acuerdo al texto de la ley, un objetivo diverso al de la reivindicación, es utilizada para recobrar el terreno desposeído aduciendo incertidumbre en los deslindes de inmuebles contiguos de propietarios distintos.

En el caso que aquí se comenta, se produce, precisamente, una discusión de este tipo. En efecto, Emilia Pairo Huisa había obtenido, anteriormente, el reconocimiento de su pretensión en un juicio de precario seguido en contra de Segundo Tarque Cossio, que había sido obligado a restituir el retazo que la actora afirmaba era parte de su propiedad y se encontraba injustamente ocupado por el demandado.

Respecto del mismo bien, el otrora demandado y otros entablan, posteriormente, acción de reivindicación en contra de Emilia Pairo, fundando su demanda

en nuestro Código Civil". Revista Chilena de Derecho. Volumen 36, No 3. 2009, pp. 523-524.

3 Recordemos que, en la gran mayoría de los casos, habiéndose adquirido el dominio mediante modos derivativos, la prueba de mayor certeza es la prescripción adquisitiva, lo que obliga a recurrir a la denominada cadena de posesiones. Al respecto, Alessandri Rodríguez, Arturo, Somarriva Undurraga, Manuel, y Vodanovic Haklicka, Antonio. Tratado de los Derechos Reales. Bienes. Tomo II. 6a Edición. Santiago: Editorial Jurídica de Chile, 2009, pp. 279 y ss., ponen de manifiesto que, a diferencia de otras realidades, como la francesa, nuestra jurisprudencia "no ha plasmado ninguna doctrina general sobre las presunciones de dominio, de manera que en cada caso la solución no está 'prefabricada' y hay que construirla paso a paso y caminando con pies de plomo".

4 En otros ordenamientos, como el español (art. 348 inciso $2^{\circ} \mathrm{CC}$ español) y el italiano (art. $948 \mathrm{CC}$ italiano), la acción reivindicatoria no sólo procede contra el poseedor no dueño sino también contra el tenedor.

5 Lo señalaban hace dos décadas Domínguez Hidalgo, Carmen y Domínguez Benavente, Ramón. "Lo que la jurisprudencia se llevó”. Revista de Derecho de la Universidad de Concepción. N 189, año LIX. Enero-junio, 1991, p.99, "la jurisprudencia se llevó la acción de dominio, aunque con vida en la letra del Código Civil. En su reemplazo, la situación de hecho contenida en el apartado $2^{\circ}$ del artículo 2.195 ha venido a ocupar el sitio de aquélla”.. 
en ser dueños del inmueble singularizado como "AA" $\mathrm{y}$ en que la demandada es propietaria de "BB" , siendo el bien disputado en el juicio de precario parte de un terreno mayor perteneciente a los actores.

En primera instancia se accede a la acción de reivindicación y, a su vez, la Corte de Apelaciones de Arica rechaza el recurso de apelación interpuesto por doña Emilia, que, por su parte, interpone casación en el fondo.

Fundamentando este último recurso, doña Emilia señala que los sentenciadores del mérito habrían excedido lo solicitado por las partes, extendiendo su decisión a un asunto distinto del que decía relación con la naturaleza de la acción impetrada en autos, efectuando un análisis y, consecuentemente, un pronunciamiento, que diría más bien relación con una acción de demarcación, en tanto declararon que el único objeto del juicio es determinar los deslindes entre los dos predios colindantes en disputa.

En efecto, el fallo habría hecho hincapié en la naturaleza de la acción de demarcación sin que esta haya sido la acción intentada por las partes. Y la Corte Suprema, a su vez, declara inadmisible el recurso de casación refiriéndose, especialmente, a la distinción entre dicha acción y la de reivindicación. La Corte señala que ambas acciones tienen objetos distintos: la primera busca que se señalen los límites de dos predios colindantes, en tanto que la segunda se interpone para recuperar un terreno cuyo dominio pretende el demandante y que está en posesión del demandado. Así -agrega-, si lo solicitado es la restitución en forma indeterminada de terrenos que están dentro de los linderos del predio que se pretende demarcar, la acción propia es la de demarcación; si lo requerido es la posesión de terrenos determinados que otro tiene en su poder y que están dentro de los linderos del que los pide, se trata entonces de una acción reivindicatoria. Además, citando a Alessandri, Somarriva y Vodanovic ${ }^{8}$, aclara que en la reivindicación se pretende tener derecho a una determinada extensión de terreno; y que, en cambio, en la acción de demarcación no se pretende una extensión de terreno definida, sino que se arguye que los límites resultantes del título o de la posesión son otros que los que afirma la parte contraria.

$\mathrm{Al}$ respecto, la Corte Suprema ha tenido pronunciamientos diversos sobre las relaciones existentes entre la acción de demarcación y la acción reivindicatoria. Así, en sentencia de 3 de abril de 2008, Rol No 206-2008, la Primera Sala de la Corte Suprema rechazó la acción de demarcación por manifiesta falta de fundamento, señalando que "el haber incoado una acción tendiente a obtener

6 Singularizado como Lote Individual $\mathrm{N}^{\circ}$ 3, del Proyecto de Parcelación Sobraya, ubicado en la comuna y provincia de Arica el cual se encuentra inscrito a sus nombres a fojas 3.064, N 2.456, del Registro de Propiedad del año 2008, del Conservador de Bienes Raíces de esa ciudad.

7 El cual se encontraba inscrito a sus nombres a fojas 3.064, Nº 2.456, del Registro de Propiedad del año 2008, del Conservador de Bienes Raíces.

8 Alessandri, Somarriva, y Vodanovic (2009), p.196. 
la demarcación y cerramiento, cuyo objetivo es fijar los límites que lo separan del o los predios colindantes, en circunstancias que el cierro existe como en autos, en forma de cerco o valla alambrada - no permite llegar a otra conclusión que no sea que la acción intentada carece de objeto, correspondiendo a una acción diversa la pretensión de desplazar ese linde con arreglo a los títulos de los que las partes se sirvan" (énfasis añadido).

Las colisiones entre acción de demarcación y acción reivindicatoria son frecuentes en la práctica. Muchas de las acciones de demarcación son rechazadas, redirigiendo al actor a la reivindicación. Las dudas acerca de la procedencia de una y otra acción se producen, especialmente, cuando el sector de deslinde confuso es de apreciable superficie y uno de los vecinos pretende alterar un estado de hecho existente por largo tiempo. En suma, parece ser que la diferencia entre una y otra acción estaría en el principal fin perseguido: fijación de deslindes (los límites resultantes del título o de la posesión son otros que los que afirma la parte contraria), en la primera, y restitución de un sector de terreno, en la segunda. Se ha señalado, como criterio de distinción por los tribunales, que si la zona conflictiva no es poseída efectivamente por ninguno de los contendores, procede la demarcación; si el terreno está siendo poseído por el vecino, y se pretende la restitución, lo que procede es la reivindicatoria.

Pues bien, la sentencia que aquí se comenta afirma que "no se desnaturaliza la acción de demarcación incorporando en ella cuestiones de dominio, pues recuperar terrenos (como consecuencia de la fijación justa y legal de los límites que separan a los predios colindantes) es uno de sus fines, siempre que no se los individualice y que su objeto principal sea la fijación de la línea divisoria, con las restituciones consiguientes, pero inciertas en su cantidad y destino [...], agregando -al hacer suyo el argumento manifestado en otro fallo anterior, que "El actor, si hace valer su derecho de dominio sobre una determinada porción de terreno, no deja de ejercitar la acción de demarcación por invocar, como antecedente de hecho, la circunstancia de que el demandado, al trazar por sí y ante sí la línea de separación, habría dejado comprendida una extensión de terreno que sobrepasa a la superficie que le correspondería de acuerdo a los títulos de dominio" (considerando octavo) (énfasis añadido).

Es decir, uno de los elementos para no confundir esta acción con la de reivindicación es la no individualización de los terrenos. Por otra parte, siguiendo a la Corte, no podría rechazarse la acción de demarcación argumentando que procede la de reivindicación, si se invoca como antecedente de hecho -y así suele suceder- que el demandado haya trazado unilateralmente la línea de separación, si con ello quedó comprendida una extensión de terreno que sobrepasa la superficie que le correspondería de acuerdo a los títulos de dominio que se presentan en la demanda. Es decir, la sentencia de la Corte admite que, bajo estos supuestos, la acción de demarcación se transforme en un medio de protección eficaz del derecho de dominio sobre un inmueble. El que lo afirme con ocasión 
de un recurso de casación en el fondo interpuesto contra sentencia recaída en juicio de reivindicación (y no de demarcación) -antecedido de una acción de precario-, da cuenta de los estrechos límites existentes entre estas acciones. 